\title{
Condom use peer norms and self-efficacy as mediators between community engagement and condom use among Chinese men who have sex with men
}

Haochu Li ${ }^{1,2,3^{*}}$, Li Xue ${ }^{1}$, Joseph D. Tucker ${ }^{2,3}$, Chongyi Wei ${ }^{4}$, Maya Durvasula ${ }^{5}$, Wenqi Hu' ${ }^{1}$ Dianming Kang ${ }^{6}$, Meizhen Liao ${ }^{6}$, Weiming Tang ${ }^{2,3,7}$ and Wei Ma ${ }^{1 *}$

\begin{abstract}
Background: Community engagement strategies are often integrated in public health interventions designed to promote condom use among men who have sex with men (MSM), a key population for HIV prevention. However, the ways in which condom use peer norms and self-efficacy play a role in the association between community engagement and condom use is unclear. This study examines the potential mediating roles of peer norms and self-efficacy in this association.

Methods: A nationwide cross-sectional online survey was conducted among Chinese MSM in 2015. Recruitment criteria included being born biologically male, being older than 16 years, having had anal sex with a man at least once during their lifetime, and having had condomless anal or vaginal sex in the past three months. Mplus 6.11 was used to conduct confirmatory factor analysis and path modeling analysis to examine the structural relationships between HIV/sexual health community engagement (e.g., joining social media and community events related to HIV and sexual health services), condom use peer norms, condom use self-efficacy, and frequency of condom use.

Results: The study found that HIV/sexual health community engagement, condom use peer norms, condom use self-efficacy, and frequency of condom use were mutually correlated. A good data model was achieved with fit index: $\mathrm{CFI}=0.988, \mathrm{TLI}=0.987, \mathrm{RMSEA}=0.032,90 \% \mathrm{Cl}(0.028,0.036)$. HIV/sexual health community engagement was associated with frequency of condom use, which was directly mediated by condom use peer norms and indirectly through self-efficacy.

Conclusion: The study suggests that condom use peer norms and self-efficacy may be mediators in the pathway between community engagement and condom use, and suggests the importance of peer-based interventions to improve condom use.
\end{abstract}

Keywords: HIV, Community engagement, Peer norm, Self-efficacy, Men who have sex with men, Path model

\footnotetext{
* Correspondence: hcli@alumni.cuhk.net; haochuli@med.unc.edu; weima@sdu.edu.cn

$\mathrm{HL}$ and LX will share "first authorship".

${ }^{1}$ Department of Epidemiology, School of Public Health, Shandong University,

44 West Wenhua Road Shandong Province, Jinan 250012, China

Full list of author information is available at the end of the article
} 


\section{Background}

Meta-analyses of randomized controlled trials (RCTs) show that behavioral interventions have not been successful in sustainably changing condom use [1, 2]. Most of these interventions focused on individual-level behavior change and did not integrate community engagement. Community engagement is defined as a process of inclusive participation of community members in order to address issues that affect the well-being of their community [3]. This approach encourages participants to transform from being passive recipients of information to active problem-solvers [4]. Activists, volunteers, and peers are encouraged to organize events that are focused on education, prevention, and care, thus strengthening support networks among members of key populations, addressing social challenges of stigmatization and discrimination, and increasing community members' perceptions of opportunities to participate in the promoted events $[5,6]$.

Community engagement is important for $\mathrm{HIV} /$ sexual health programs for three reasons: (1) it provides psychosocial benefits for participants, including increased senses of belonging [7] and empowerment [8], and decreased perceptions of stigma and isolation [9]; (2) it provides opportunities for capacity building [10]; and (3) it aids in the development of long-term community projects and networks, which remain in place after interventions end [11]. HIV/sexual health community engagement has been linked to increased condom use [12], increased HIV testing [13], improved linkage to care [14], greater access to treatment [15], and improved retention in care [16].

Studies have found a significant association between community engagement and individual-level condom use among MSM [17-20]. However, there is a relatively limited understanding of the factors that mediate this association, which may hinder efforts by health care professionals to develop effective community engagement campaigns that promote condom use. Studies have indicated that both peer norms and self-efficacy are important constructs in predicting human social behaviors and may serve as mediators between community engagement and condom use [6, 21-23]. Studies of MSM from Europe and the United States report positive intervention results in the form of safer sex practices, following efforts to strengthen mediators like norms and self-efficacy that facilitate behavioral change $[24,25]$.

Condom use peer norms are the expected patterns of behavior and attitudes toward condom use among one's peers. Condom use self-efficacy is one's confidence in one's own ability to adhere to condom use guidelines in challenging situations $[6,23]$. Peer norms are an important construct in the theory of reasoned actions and the theory of planned behavior, and self-efficacy is a core construct in social cognitive theory (SCT) [21, 26, 27].
Both peer norms and self-efficacy are strong predictors of condom use [28]. However, the theoretical constructs of peer norms and self-efficacy that apply in one context may not necessarily be applicable in another, given variation in factors like gender, ethnicity, and culture/ subculture [29, 30].

In order to better understand how community engagement can contribute to the HIV response, it is important to investigate the ways in which community engagement influences peer norms and self-efficacy and promotes safe sexual behavior $[17,31,32]$. The purpose of this study is to answer the following questions, for a sample of Chinese MSM: does HIV/sexual health community engagement predict condom use or does it predict behavior via peer norms and self-efficacy? Second, are there indirect effects of community engagement on self-efficacy via peer norms? Third, are there direct effects of peer norms on condom use or indirect effects via self-efficacy?

\section{Methods \\ Study population and procedure}

A nationwide cross-sectional online survey of MSM was conducted in China from November 2 to 7 2015. In order to recruit participants from across the country, survey recruitment was done through popular online social networking platforms: Danlan.org, the largest gay web portal in China, and its associated gay mobile dating app; Weibo, a microblogging platform; and WeChat, a messaging app. Participants entered the survey by clicking on a banner ad, which directed them to a survey hosted on Qualtrics (Provo, Utah). The survey was anonymous and voluntary. Inclusion criteria included: being born biologically male, having had anal sex with a man at least once during their lifetime, having had condomless anal or vaginal sex in the past three months, and being at least 16 years of age. Informed consent was obtained from all eligible participants before they began the survey. Ethics approval was granted by institutional review boards at the Guangdong Provincial Centre for Skin Diseases and STI Control, China, the University of North Carolina at Chapel Hill, and the University of California, San Francisco.

\section{Measurements}

The survey instrument was adapted from a previous online survey administered to Chinese MSM that included questions on sexual history, HIV/STI testing, and risk behaviors. The survey instrument was designed iteratively, with preliminary input from local stakeholders, sociologists, and physicians, as well as 60 MSM [33]. Survey questions were further modified based on the results of a comprehensive literature search, input from researchers who designed similar previous surveys, and two rounds of 
field-testing. A revised survey instrument was piloted with 150 MSM before the final survey was launched.

\section{HIV/sexual health community engagement}

Community engagement was measured using an eightitem scale, adapted from community engagement literature [34-36] and piloted on 150 Chinese MSM. The scale items included: traditional engagement, which includes participation in volunteer activities that help others access HIV and sexual health services; and technology-based engagement, which includes watching videos and participating in discussions on social media about sexual health, HIV/STI prevention and care, and condom use (See Additional file 1: Table S1 for the detailed). Latent variable modeling was used to test the scale's reliability and the corresponding alpha value was 0.720 (95\% CI 0.692-0.749) [37]. The mean was calculated for the eight items, each of which had binary answers (Yes $=1$, No $=0$ ), with a possible high score of 1 and a possible low score of 0 . Higher mean scores indicated higher self-reported levels of community engagement.

\section{Condom use peer norms}

Peer norms for condom use were measured using a sixitem scale [38]. Questions included participants' perceptions of their friends' attitudes towards condom use and safe sex. For example, participants were asked to evaluate the following statement: "If I had sex and told my friends that I did not use a condom, they would be angry or disappointed." Answers were given in a five-point Likert format: strongly agree (5), agree (4), neutral (3), disagree (2), strongly disagree (1) (See Additional file 1: Table S2 for the detailed). In the present study, the Cronbach's alpha value was 0.770 . The mean was calculated with a possible high score of 5 and a possible low score of 1. Higher mean scores indicated higher self-reported strength of condom use peer norms.

\section{Condom use self-efficacy}

Condom use self-efficacy was measured using a sevenitem scale [39]. Participants were asked how comfortable they felt about negotiating and using a condom with sex partners. For example, participants were asked to evaluate the following statement: "I feel confident that I could refuse to have sex with a partner who did not want me to use a condom." Answers were given in a five-point Likert format: Strongly agree (5), agree (4), neutral (3), disagree (2), strongly disagree (1) (See Additional file 1: Table S3 for the detailed). In the present study, the Cronbach's alpha value was 0.823 . The mean was calculated with a possible high score of 5 and a possible low score of 1 . Higher mean scores indicated higher selfreported strength of condom use self-efficacy.

\section{Condom use}

Frequency of condom use with four types of sex partners (primary male partner, casual male partner, primary female partner, and casual female partner) was evaluated using four survey items [40]. For example, participants were asked to evaluate the following statement: "In the last three months, when you had sex with a male casual partner, how frequently did you or your partner use condoms?" Answers were given in a four-point Likert format: Always used (4), mostly used (3), sometimes used (2), never used (1). In the present study, frequency of condom use was treated as an observed variable, instead of a latent variable [41]. The mean was calculated with a possible high score of 4 and a possible low score of 1 . Higher mean scores indicated higher self-reported frequency of condom use.

\section{Statistical analyses}

First, SPSS 19 was used to conduct a descriptive analysis of participants' sociodemographic characteristics. Spearmen correlation tests were used to test the associations among the four variables (i.e., HIV/sexual health community engagement, condom use peer norms, condom use self-efficacy, and frequency of condom use). Second, Mplus 6.11 was used to conduct confirmatory factor analysis (CFA) to assess construct validity of the items and assess the goodness of fit of the measurement model. Third, we applied structural equation modeling (SEM) to examine the pathways of our hypothesized model. All items assumed to reflect latent factors (i.e., HIV/sexual health community engagement, condom use peer norm, and condom use self-efficacy) were defined as categorical variables. We used the robust weighted least squares (WLSMV) estimator, available in Mplus [42]. Fourth, we ran an initial model, which regressed condom use on community engagement, social norm, self-efficacy, and marital status (a sociodemographic variable related to condom use in correlation analysis). Results indicated that the coefficients on "condom use on community engagement" and "condom use on peer norm" were not significant at $p<0.1$. For subsequent analyses, we removed these non-significant regression paths. Fifth, modification indices $(\mathrm{MI}>25)$ were examined to identify missing paths and seven covariate paths among indicators were added step by step. We then reached the final good data model. The overall model fit was examined by using the comparative fit index (CFI) and the root mean square error of approximation (RMSEA). For the CFI, values greater than 0.95 indicate a good model fit, and for RMSEA, a value below 0.06 indicates good fit [43]. The indirect effects were calculated using the Delta method in Mplus [42]. 


\section{Results}

In total, 7892 people clicked the banner link to the survey, and 7551 (96\%) began the survey. Of the 1597 participants who met inclusion criteria and provided informed consent, 1189 participants completed the survey. However, 147 participants did not answer any questions about frequency of condom use. A total of 1042 participants were included in the current data analysis.

\section{Sample characteristics}

Among the 1042 participants, the mean age was $25.3 \pm 6.77 ; 62.4 \%$ were $\leq 25$ years of age; $13.3 \%$ were currently married to a woman or engaged; $35.0 \%$ were students; $67.6 \%$ had a college diploma or higher level of education; $81.1 \%$ had a monthly income less than 806.5 USD (5000 RMB); $70.3 \%$ identified as gay while $25.9 \%$ identified as bisexual (Table 1). A descriptive cross-table for sociodemographic variables, community engagement, peer norms, self-efficacy, and condom use is also provided (see Additional file 1: Table S4).

\section{Bivariate correlations between community engagement, peer norms, self-efficacy and condom use}

The mean score for community engagement was 0.35 $(\mathrm{SD}=0.25)$. The mean score for condom use peer norms was $3.75(\mathrm{SD}=0.71)$. The mean score for condom use self-efficacy use was $3.98(\mathrm{SD}=0.68)$. The mean score for condom use was $2.37(\mathrm{SD}=1.00)$ (Table 2). Results in Table 3 indicate that the predictor variable of community engagement was significantly correlated with both mediators, condom use peer norms $\left(r_{s}=0.152, p<0.001\right)$ and condom use self-efficacy $\left(r_{s}=0.140, p<0.001\right)$, and the outcome variable of condom use $\left(r_{s}=0.085, p<0.01\right)$. Furthermore, the two mediators were also significantly correlated with the outcome variable $\left(r_{s}=0.148, p<0.001\right.$; $\left.r_{s}=0.254, p<0.001\right)$, supporting the proposed mediation model.

\section{Measurement model of community engagement, peer norms and self-efficacy}

Confirmatory factor analysis showed that all items loaded significantly on their corresponding factors (all loadings $P<0.01$ ) (Table 4). A test of the measurement model resulted in the following fit index: $\mathrm{CFI}=0.960$, TLI $=0.954$, RMSEA $=0.064,90 \%$ CI $(0.060,0.068)$, indicating good fit. Standardized factor loading of the modified measurement model ranged from 0.229 to 0.935 . All were statistically significant at $p<0.001$.

\section{Structured Path Model of Community Engagement, Peer Norms, Self-Efficacy and Condom Use}

Results in Fig. 1 indicate a good data model with fit index: $\mathrm{CFI}=0.988, \mathrm{TLI}=0.987$, $\mathrm{RMSEA}=0.032,90 \% \mathrm{CI}$ $(0.028,0.036)$. Community engagement was associated
Table 1 Sociodemographic characteristics of online high-risk MSM in China, 2015 ( $n=1042)$

\begin{tabular}{|c|c|c|}
\hline Characteristics & $\begin{array}{l}\text { Frequency } \\
(N=1042)\end{array}$ & Percentage (\%) \\
\hline \multicolumn{3}{|l|}{$\overline{\text { Age }^{a}}$} \\
\hline$\leq 25$ & 648 & 62.4 \\
\hline $26-35$ & 306 & 29.5 \\
\hline $36-45$ & 67 & 6.4 \\
\hline$\geq 46$ & 18 & 1.7 \\
\hline \multicolumn{3}{|l|}{ Marital status } \\
\hline Not married & 853 & 81.9 \\
\hline Engaged or Married & 139 & 13.3 \\
\hline Separated or Divorced & 48 & 4.6 \\
\hline Widowed & 2 & 0.2 \\
\hline \multicolumn{3}{|l|}{ Student status } \\
\hline Yes & 365 & 35.0 \\
\hline No & 677 & 65.0 \\
\hline \multicolumn{3}{|l|}{ Education level } \\
\hline High school or below & 338 & 32.4 \\
\hline College diploma & 264 & 25.3 \\
\hline Undergraduate & 390 & 37.4 \\
\hline Postgraduate (Master/PhD) & 50 & 4.8 \\
\hline \multicolumn{3}{|l|}{ Individual monthly income } \\
\hline < 1500 RMB (241.9 USD) & 276 & 26.5 \\
\hline 1500-3000 RMB (242-483.9 USD) & 269 & 25.8 \\
\hline 3001-5000 RMB (484-806.5 USD) & 300 & 28.8 \\
\hline 5001-8000 RMB (806.6-1290 USD) & 100 & 12.5 \\
\hline > 8000 RMB (1290 USD) & 67 & 6.4 \\
\hline \multicolumn{3}{|l|}{ Sexual identity } \\
\hline Gay & 733 & 70.3 \\
\hline Bisexual & 270 & 25.9 \\
\hline Straight/Heterosexual & 1 & 0.1 \\
\hline Unsure/Other & 38 & 3.6 \\
\hline
\end{tabular}

${ }^{a}$ Age: mean $=25.3, S D= \pm 6.767$ (with three missing values)

with condom use peer norms $(b=0.198, p<.001)$ and marginally associated with self-efficacy $(b=0.063, p<.1)$. The two mediators were significantly associated with each other $(b=0.646, p<.001)$. Only self-efficacy was significantly associated with the outcome variable $(b=0.274$, $p<.001)$. The model explained $8.5 \%$ of the variance in

Table 2 Descriptive statistics of four variables

\begin{tabular}{llllllll}
\hline & Mean(SD) & Min & Q25 & Median & Q75 & Max & $N$ \\
\hline Engagement & $0.35(0.25)$ & 0.00 & 0.13 & 0.25 & 0.5 & 1.00 & 1042 \\
Peer norms & $3.75(0.71)$ & 1.00 & 3.33 & 3.67 & 4.33 & 5.00 & 1042 \\
Self-efficacy & $3.98(0.68)$ & 1.43 & 3.57 & 4.00 & 4.57 & 5.00 & 1042 \\
Condom use & $2.37(1.00)$ & 1.00 & 1.50 & 2.00 & 3.00 & 4.00 & 1042 \\
\hline
\end{tabular}


Table 3 Correlations between variables of community engagement, peer norms, self-efficacy and condom use among online high-risk MSM in China, 2015 ( $n=1042)$

\begin{tabular}{llll}
\hline Variable & 2 & 3 & 4 \\
\hline 1.community engagement & $0.152^{* * *}$ & $0.140^{* * *}$ & $0.085^{* *}$ \\
2.peer norms & & $0.516^{* * *}$ & $0.148^{* * *}$ \\
3.self-efficacy & & $0.254^{* * *}$ \\
4.condom use & & \\
\hline *** $p<0.001{ }^{* *} p<0.01$ & & &
\end{tabular}

condom use. The estimated mediation effect between community engagement and condom use via peer norms and self-efficacy was $0.052(p<0.001$; Table 5$)$. The mediation effects via specific paths are shown in Table 5.

\section{Discussion}

This study tested the proposed mediating roles of condom use peer norms and self-efficacy in the association between HIV/sexual health community engagement and

Table 4 Unstandardized and standardized loading for measurement model of community engagement, peer norms and self-efficacy among online high-risk MSM in China $(n=1042)$

\begin{tabular}{lll}
\hline Parameter estimate & Unstandardized loading(SE) & Standardized loading \\
\hline Engagement $\rightarrow$ I1 & 1.000 & 0.809 \\
Engagement $\rightarrow$ I2 & $0.902(0.052)^{* * *}$ & 0.745 \\
Engagement $\rightarrow$ I3 & $0.700(0.045)^{* * *}$ & 0.566 \\
Engagement $\rightarrow$ I4 & $1.088(0.047)^{* * *}$ & 0.880 \\
Engagement $\rightarrow$ I5 & $1.088(0.052)^{* * *}$ & 0.880 \\
Engagement $\rightarrow$ I6 & $0.667(0.051)^{* * *}$ & 0.539 \\
Engagement $\rightarrow$ I7 & $0.697(0.051)^{* * *}$ & 0.564 \\
Engagement $\rightarrow$ I8 & $0.580(0.053)^{* * *}$ & 0.469 \\
Peer norms $\rightarrow$ F3 & 1.000 & 0.229 \\
Peer norms $\rightarrow$ F4 & $2.507(0.336)^{* * *}$ & 0.574 \\
Peer norms $\rightarrow$ F5 & $2.650(0.356)^{* * *}$ & 0.606 \\
Peer norms $\rightarrow$ F6 & $3.740(0.494)^{* * *}$ & 0.856 \\
Peer norms $\rightarrow$ F7 & $3.827(0.501)^{* * *}$ & 0.875 \\
Peer norms $\rightarrow$ F8 & $4.086(0.538)^{* * *}$ & 0.935 \\
Self-efficacy $\rightarrow$ F9 & 1.000 & 0.727 \\
Self-efficacy $\rightarrow$ F10 & $0.932(0.033)^{* * *}$ & 0.678 \\
Self-efficacy $\rightarrow$ F11 & $0.963(0.033)^{* * *}$ & 0.700 \\
Self-efficacy $\rightarrow$ F12 & $1.048(0.031)^{* * *}$ & 0.761 \\
Self-efficacy $\rightarrow$ F13 & $0.993(0.029)^{* * *}$ & 0.721 \\
Self-efficacy $\rightarrow$ F14 & $0.958(0.030)^{* * *}$ & 0.696 \\
Self-efficacy $\rightarrow$ F15 & $0.954(0.031)^{* * *}$ & 0.694
\end{tabular}

As suggested by the modification indices, adjustment of original CFA model is not needed

Standard errors are in the parenthesis

*** $p<0.001$, Fit index: $\mathrm{CFI}=0.960, \mathrm{TLI}=0.954, \mathrm{RMSEA}=0.064,90 \% \mathrm{C}$ $(0.060,0.068)$ frequency of condom use. The hypothesized structural path model was tested using data from a nationwide online survey with a sample of 1042 sexually active MSM in China. The proposed mediation relationship was supported by correlation analysis and confirmed by structural path modeling analysis, which support the need for additional longitudinal studies to assess causality in the relationship. The study findings add to the existing literature by demonstrating the potential indirect effect of community engagement on self-efficacy via peer norms, and the potential indirect effect of peer norms on condom use via self-efficacy. This study provides insight about the ways in which future public health interventions geared towards condom use ought to be designed.

The results suggest that HIV/sexual health community engagement may not directly impact condom use selfefficacy among sexually active MSM in China. Instead, community engagement may indirectly impact condom use self-efficacy via condom use peer norms. Scholars have argued that the Chinese are socialized to adhere to social norms and cultural rules, with peer norms influencing individuals' beliefs, attitudes, and behaviors $[44,45]$. Among sexually active Chinese MSM, ethnographies have found that peer norms in some gay settings influenced subjects' beliefs and self-efficacy in regard to condom use $[46,47]$. When MSM participate in HIV/sexual health community events and, subsequently, develop positive perceptions of their friends' attitudes towards condom use and safe sex, they may improve their self-efficacy for condom use. Stronger perceptions of peer norms may increase one's self-efficacy in regard to condom use [48, 49]. This is a potential way in which community engagement may influence self-efficacy by altering perceptions of peer norms regarding condom use.

The results of this study also suggest that within the association between community engagement and condom use, peer norms may have an indirect effect on condom use via self-efficacy. This finding extends our knowledge about these relationships from previous studies, in which the existence of peer norms and self-efficacy were reported only as predictors of condom use [28, 50]. Studies have identified self-efficacy alone as a mediator of the intervention effect for condom use [24, 49, 51]. Moreover, a study showed that while peer norms and self-efficacy were both significantly associated with condom use in bivariate analysis, only self-efficacy remained significant in multivariate analysis [48]. Our path analysis suggests that peer norms are not sufficient to influence condom use directly. While self-efficacy for condom use may be a core mediator, peer norms act through self-efficacy in order to impact condom use. The central role of self-efficacy in a mediating relationship has been confirmed, which is consistent with other empirical mediating analyses on selfefficacy, $[49,52]$ as well as theoretical arguments $[53,54]$. 


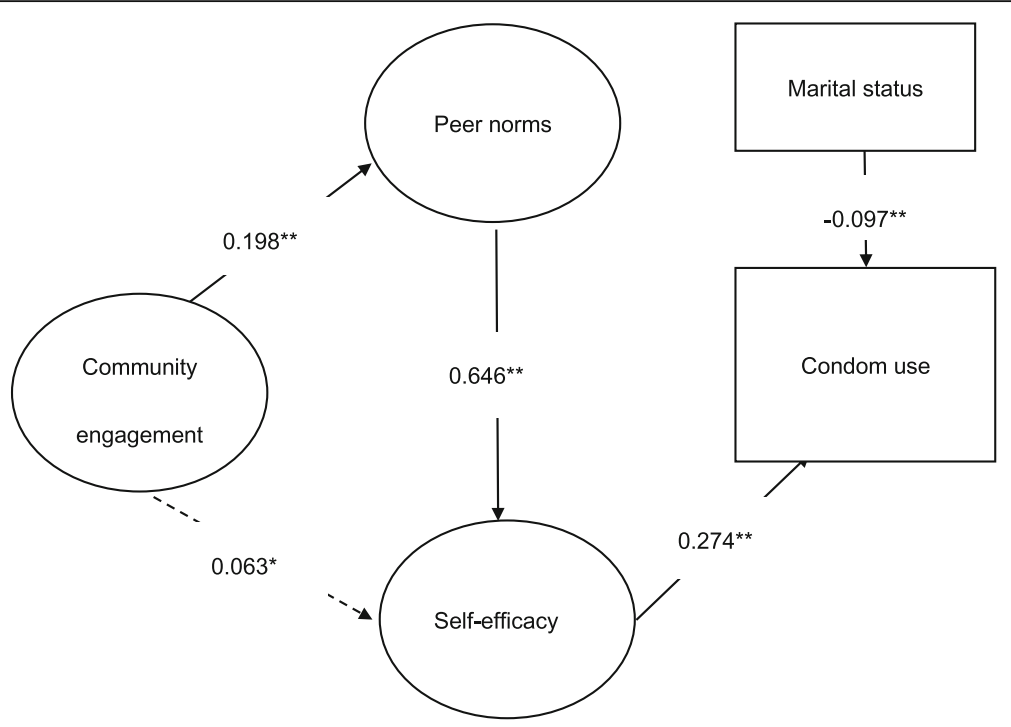

Fig. 1 Structured path model of community engagement, peer norms, self-efficacy and condom use among online high-risk MSM in China, 2015 $(n=1042)$. Path model of community engagement, peer norm, self-efficacy, and condom use ${ }^{* *} p<0.001,{ }^{*} p<0.1$. Note: Fit index: CFI $=0.988$, $\mathrm{TLI}=0.987, \mathrm{RMSEA}=0.032,90 \% \mathrm{Cl}(0.028,0.036)$. Only significant routes were included in the figure. All path coefficients and factor loadings shown were standardized

The present study has implications for the design of public health interventions. First, our results suggest that $\mathrm{HIV} /$ sexual health community engagement can enhance condom use peer norms and self-efficacy, thus impacting condom use behavior. These findings encourage integrating community engagement approaches into HIV prevention programs. Previous studies have examined only traditional approaches to community engagement and excluded online engagement through social media platforms $[12,17,20]$. Our study suggests including online and social media activities related to $\mathrm{HIV} /$ sexual health and condom use alongside traditional community engagement approaches. This is an active response to the rapid development of online communities and social media interactions among MSM in China. Moreover, the integration of both traditional community events and online social media activities may offer broader opportunities to address stigma and discrimination against MSM. Other studies have also encouraged these combined approaches to interventions $[55,56]$.
Second, our study suggests that community engagement has an indirect effect on condom use by impacting peer norms and self-efficacy for condom use. When community engagement is utilized to promote condom use, it is important to include concepts of peer norms and self-efficacy for condom use into the design and programming of the intervention campaign. Our study also encourages the integration of peer intervention $[25,57]$ programs within community engagement campaigns in order to strengthen condom use peer norms and self-efficacy.

Our study has several limitations. First, this analysis relied on cross-sectional data, limiting our ability to assess causality. Second, the data were obtained from an online survey with participants who tended to be relatively young and well educated. Moreover, we only recruited high-risk MSM, which limited our ability to assess the MSM population in China, but allowed the analysis to focus on HIV prevention for the key population. Finally, the frequency of condom use was measured using self-reported data, so social desirability bias may be a concern.

Table 5 Indirect effects of community engagement on condom use via peer norms and self-efficacy among online high-risk MSM in China, 2015 ( $n=1042)$

\begin{tabular}{lllll}
\hline Pathways to condom use & Unstandardized $\beta$ & SE & $P$ value & Standardized $\beta$ \\
\hline Engagement - self-efficacy - condom use & 0.040 & 0.024 & 0.099 & 0.017 \\
Engagement-peer norms - self-efficacy -condom use & 0.081 & 0.023 & 0.000 & 0.035 \\
Total indirect effect of engagement & 0.121 & 0.033 & 0.000 & 0.052 \\
Peer norms - self-efficacy - condom use & 0.757 & 0.142 & 0.000 & 0.177 \\
\hline
\end{tabular}

With WLSMV, Mplus doesn't provide standard errors and $p$-values for standardized estimates when the model contains covariates 


\section{Conclusions}

In sum, our study contributes to the literature by supporting and presenting the potential mediating roles of condom use peer norms and self-efficacy between HIV/sexual health community engagement and frequency of condom use. This study identifies the indirect effect of community engagement on self-efficacy via peer norms and the indirect effect of peer norms on condom use via self-efficacy. In terms of intervention design, the results indicate that effective community engagement campaigns should incorporate both online social media activities and traditional community events in order to address stigma and discrimination against MSM. The study encourages adopting peer interventions to promote condom use.

\section{Additional file}

Additional file 1: Table S1. Eight items of HIV/ sexual health community engagement among high-risk MSM in China, 2015 ( $n=1042)$. Table S2. Six items of condom use peer norm among high-risk MSM in China, 2015 $(n=1042)$. Table S3. Seven items of condom use self-efficacy among high-risk MSM in China, 2015 ( $n=1042$ ). Table S4 Descriptive cross-table for sociodemographic variables, community engagement, peer norms, self-efficacy, and condom use (DOCX $20 \mathrm{~kb}$ )

\section{Abbreviations \\ CFA: Confirmatory factor analysis; CFI: Comparative fit index; Cl: Confidence interval; HIV: Human immunodeficiency virus; Ml: Modification indices; MSM: Men who have sex with men; RCT: Randomized controlled trial; RMB: Ren min bi; RMSEA: Root mean square error of approximation; SD: Standardized deviation; SEM: Structural equation modeling; SPSS: Software package for statistical analysis; STI: Sexually transmitted infections; TLI: Tucker Lewis index; USD: United states dollar; WLSMV: Robust weighted least squares}

\section{Acknowledgements}

We appreciate the men who participated in this study and would like to thank Drs. Frank Wong and Xinguang Chen for comments and advice. The content of the article is solely the responsibility of the authors and does not necessarily represent the official views of the National Institutes of Health.

\section{Funding}

This work was supported by the National Institutes of Health [National Institute of Allergy and Infectious Diseases 1R01Al114310]; UNC-South China STD Research Training Centre [Fogarty International Centre 1D43TW009532 to JT]; UNC Center for AIDS Research [National Institute of Allergy and Infectious Diseases 5P30AI050410]; the UNC Chapel Hill, Johns Hopkins University, Morehead School of Medicine and Tulane University (UJMT) Fogarty Fellowship [FIC R25TW0093]; and American Psychological Association's Cyber Mentors Program [National Institute of Mental Health R25-MH083635]. The listed grant funders played no role in any step of this study.

\section{Availability of data and materials}

The data supporting our findings have been presented in the main text.

\section{Authors' contributions}

$H L, W M, J T, C W, D K$, and ML performed research design. $H L$, DK and ML conducted data collection. $H \mathrm{~L}, \mathrm{LX}$, and WH conducted data analysis. $\mathrm{HL}, \mathrm{JT}$, CW, MD, WM, and WT drafted and modified this manuscript. All authors read and approved the final manuscript.

\section{Ethics approval and consent to participate}

Ethical approval was granted by Institutional Review Board of the University of North Carolina, Chapel Hill; University of California, San Francisco; Shandong University, Shandong Center for Disease Control and Prevention, and
Guangdong Provincial Center for Skin Diseases and STI Control. Written informed consent has been obtained from all participants.

\section{Consent for publication}

Not applicable.

\section{Competing interests}

The authors declare that they have no competing interests.

\section{Publisher's Note}

Springer Nature remains neutral with regard to jurisdictional claims in published maps and institutional affiliations.

\section{Author details}

${ }^{1}$ Department of Epidemiology, School of Public Health, Shandong University, 44 West Wenhua Road Shandong Province, Jinan 250012, China. ${ }^{2}$ UNC Project-China, Institute for Global Health and Infectious Diseases, University of North Carolina at Chapel Hill, Chapel Hill, NC, USA. ${ }^{3}$ SESH Global, Guangzhou, China. ${ }^{4}$ Department of Epidemiology and Biostatistics, University of California, San Francisco, CA, USA. ${ }^{5}$ Department of Economics, Duke University, Durham, NC, USA. ${ }^{6}$ Shandong Provincial Center for Disease Control and Prevention, Jinan, China. ${ }^{7}$ Guangdong Provincial Center for Skin Diseases and STI Control, Guangzhou, China.

Received: 27 October 2016 Accepted: 1 August 2017

Published online: 07 August 2017

\section{References}

1. Shepherd J, Kavanagh J, Picot J, et al. The effectiveness and cost-effectiveness of behavioural interventions for the prevention of sexually transmitted infections in young people aged 13-19: a systematic review and economic evaluation. Health Technol Assess. 2010;14(7):20-2.

2. Bailey JV, Murray E, Rait G, et al. Interactive computer-based interventions for sexual health promotion. Cochrane Database Syst Rev. 2010;(9): CD006483. doi:10.1002/14651858.CD006483.pub2.

3. Ahmed SM, Palermo AG. Community engagement in research: frameworks for education and peer review. Am J Public Health. 2010;100(8):1380-7.

4. Campbell C, Scott K, Nhamo M, et al. Social capital and HIV competent communities: the role of community groups in managing HIV/AIDS in rural Zimbabwe. AIDS Care. 2013;25(Suppl 1):S114-22.

5. Ramirez-Valles J. The protective effects of community involvement for HIV risk behavior: a conceptual framework. Health Educ Res. 2002;17(4):389-403.

6. Letsie PR, Halele D. Theoretical perspectives on community engagement in HIV prevention and programming among the Basotho tribe. Stud Tribes Tribals. 2012;10(1):73-82

7. Rawstorne P, Prestage G, Grierson J, Song A, Grulich A, Kippax S. Trends and predictors of HIV-positive community attachment among PLWHA. AIDS Care. 2005;17(5):589-600.

8. Roy CM, Cain R. The involvement of people living with HIV/AIDS in community-based organizations: contributions and constraints. AIDS Care. 2001;13(4):421-32

9. Harrington KF, Diclemente RJ, Wingood GM, Crosby RA, Person S, Oh MK. Validity of self-reported sexually transmitted diseases among African American female adolescents participating in an HIV/STD prevention intervention trial. Sex Transm Dis. 2001;28(8):468-71.

10. Joint United Nations Programme on HIV/AIDS(UNAIDS), Global Advocacy for HIV Prevention (AVAC). The Good Participatory Practice Guidelines for Biomedical HIV Prevention Trials, 2nd ed. 2011. http://www.unaids.org/sites/ default/files/media_asset/JC1853_GPP_Guidelines_2011_en_0.pdf.

11. Prevention CfDCa. Principles of community engagement. 2nd ed. Atlanta: CDC/ATSDR Committee on Community Engagement; 2011. https://www. atsdr.cdc.gov/communityengagement/pdf/PCE_Report_508_FINAL.pdf.

12. Galbraith J, Ricardo I, Stanton B, Black M, Feigelman S, Kaljee L. Challenges and rewards of involving community in research: an overview of the "Focus on Kids" HIV Risk Reduction Program. Health Educ Q. 1996;23(3):383-94.

13. Simon G, Nyamukapa CA, Lorraine S, Owen M, Catherine C. Grassroots community organizations' contribution to the scale-up of HIV testing and counselling services in Zimbabwe. AIDS. 2013;27(10):1657-66.

14. Hatcher AM, Turan JM, Leslie HH, et al. Predictors of Linkage to Care Following Community-Based HIV Counseling and Testing in Rural Kenya. AIDS Behav. 2012;16(5):1295-307. 
15. Ayala G, Makofane K, Santos GM, et al. Access to Basic HIV-Related Services and PrEP Acceptability among Men Who Have sex with Men Worldwide: Barriers, Facilitators, and Implications for Combination Prevention. J Sex Transm Dis. 2013:2013:953123.

16. Aliyu MH, Blevins $M$, Audet CM, et al. Integrated prevention of mother-to-child HIV transmission services, antiretroviral therapy initiation, and maternal and infant retention in care in rural north-central Nigeria: a cluster-randomised controlled trial. Lancet HIV. 2016;3(5):e202-11.

17. Saggurti N, Mishra RM, Proddutoor L, et al. Community collectivization and its association with consistent condom use and STI treatment-seeking behaviors among female sex workers and high-risk men who have sex with men/ transgenders in Andhra Pradesh, India. AIDS Care. 2013;25(Suppl 1):S55-66.

18. Jobson G, Swardt GD, Rebe K, Struthers H, Mcintyre J. HIV Risk and Prevention Among Men Who Have Sex with Men (MSM) in Peri-Urban Townships in Cape Town, South Africa. AIDS Behav. 2013;17 Suppl 1(1):12-22.

19. Tucker A, Liht J, Swardt GD, et al. An exploration into the role of depression and self-efficacy on township men who have sex with men's ability to engage in safer sexual practices. AIDS Care. 2013;25(10):1227-35.

20. Batist E, Brown B, Scheibe A, Baral SD, Bekker LG. Outcomes of a communitybased HIV-prevention pilot programme for township men who have sex with men in Cape Town, South Africa. J Int AIDS Soc. 2013;16 Suppl 3:18754.

21. Bandura A. Social foundations of thought and action: a social cognitive theory. J Appl Psychol. 1986;12(1):169-71.

22. Ajzen I. The theory of planned behaviour: Reactions and reflections. Psychol Health. 2011;26(9):1113-27.

23. Zungu-Dirwayi N, Foundation WKK. An audit of HIV/AIDS policies in Botswana. HSRC: Lesotho, Mozambique, South Africa, Swaziland and Zimbabwe; 2004.

24. Nostlinger C, Platteau T, Bogner J, et al. Computer-Assisted Intervention for Safer Sex in HIV-Positive Men Having Sex With Men: Findings of a European Randomized Multi-Center Trial. J Acquir Immune Defic Syndr. 2016;71(3):e63-72.

25. Jemmott JB 3rd, Jemmott LS, O'Leary A, et al. On the Efficacy and Mediation of a One-on-One HIV Risk-Reduction Intervention for African American Men Who Have Sex with Men: A Randomized Controlled Trial. AIDS Behav. 2015;19(7):1247-62.

26. Ajzen I, Fishbein M. Understanding attitudes and predicting social behavior. Prentice Hall: Englewood Cliffs, NJ; 1980

27. Ajzen I. Attitudes, personality, and behavior. Chicago: Open University Press; 1988.

28. Xiao Z. Correlates of condom use among chinese college students in hunan province. AIDS Educ Prev. 2012;24(5):469-82

29. Eaton L, Flisher AJ, Aarø LE. Unsafe sexual behaviour in South African youth. Soc Sci Med. 2003:56(1):149-65.

30. Jemmott JBI, Jones JM. Social psychology and AIDS among ethnic minority individuals: Risk behaviors and strategies for changing them. In: Reeder JBPGD, editor. The social psychology of HIV infection. Hillsdale: Erlbaum; 1993. p. 183-224.

31. Blankenship KM, West BS, Kershaw TS, Biradavolu MR. Power, community mobilization, and condom use practices among female sex workers in Andhra Pradesh, India. AIDS. 2008;22(Suppl 5):S109-16.

32. Cornish F, Ghosh R. The necessary contradictions of 'community-led' health promotion: a case study of HIV prevention in an Indian red light district. Soc Sci Med. 2007:64(2):496-507.

33. Han $\mathrm{L}$, Bien $\mathrm{CH}$, Wei $\mathrm{C}$, et al. HIV self-testing among online MSM in China: implications for expanding HIV testing among key populations. J Acquir Immune Defic Syndr. 2014;67(2):216-21.

34. Riehman KS, Kakietek J, Manteuffel BA, et al. Evaluating the effects of community-based organization engagement on HIV and AIDS-related risk behavior in Kenya. AIDS Care. 2013;25(Suppl 1):S67-77.

35. Chuang DM, Lacombe-Duncan A. Community engagement among men who have sex with men living with HIV/AIDS in Taiwan. AIDS Care. 2016;28(4):445-9.

36. Ko NY, Hsieh $\mathrm{CH}$, Wang MC, et al. Effects of Internet Popular Opinion Leaders (iPOL) Among Internet-Using Men Who Have Sex With Men. J Med Internet Res. 2013;15(2):458-9.

37. Raykov T, Dimitrov DM, Asparouhov T. Evaluation of Scale Reliability with Binary Measures Using Latent Variable Modeling. Struct Equ Model. 2010:17(2):265-79.

38. Dehart DD, Birkimer JC. Trying to practice safer sex: Development of the Sexual Risks Scale. J Sex Res. 1997;34(1):11-25.

39. Brafford $L$, Beck KH. Development and validation of a condom self-efficacy scale for college students. J Am Coll Heal. 1991:39(5):219-25.
40. Tang W, Han L, Best J, et al. Crowdsourcing HIV Test Promotion Videos: A Noninferiority Randomized Controlled Trial in China. Clin Infect Dis. 2016;62(11):1436-42. doi:10.1093/cid/ciw171.

41. Harper GW, Wade RM, Onyango DP, et al. Resilience among gay/bisexual young men in Western Kenya: psychosocial and sexual health outcomes. AIDS. 2015;29 Suppl 3.

42. Brown TA. Confirmatory factor analysis for applied research: second edition. Guilford Pubn; 2015. p. 353-5.

43. Hu L, Bentler PM. Cutoff Criteria for Fit Indexes in Covariance Structure Anaysis: Conventional Criteria Versus New Alternatives. Struct Equ Model. 1999;6(1):1-55.

44. Triandis HC. Individualism \& collectivism. Boulder: Westview Press; 1995.

45. Smith PB, Wang ZM. Chinese leadership and organizational structures. In: Bond M, editor. Chinese psychology. Hong Kong: Oxford University Press; 1996. p. 322-37.

46. Li H, Holroyd E, Lau J. Exploring Unprotected Anal Intercourse among Newly Diagnosed HIV Positive Men Who Have Sex with Men in China: An Ethnographic Study. PLoS One. 2015;10(10):e0140555.

47. Li H, Lau JT, Holroyd E, Yi H. Sociocultural facilitators and barriers to condom use during anal sex among men who have sex with men in Guangzhou, China: an ethnographic study. AIDS Care. 2010;22(12):1481-6.

48. Newcomb ME, Mustanski B. Cognitive influences on sexual risk and risk appraisals in men who have sex with men. Health Psychol. 2014;33(7):690-8.

49. Safren SA, Traeger L, Skeer MR, et al. Testing a social-cognitive model of HIV transmission risk behaviors in HIV-infected MSM with and without depression. Health Psychol. 2010:29(2):215-21.

50. D'Anna LH, Warner L, Margolis AD, et al. Consistency of Condom Use During Receptive Anal Intercourse Among Women and Men Who Have Sex With Men: Findings From the Safe in the City Behavioral Study. Sex Transm Dis. 2015:42(7):393-9.

51. Traeen B, Hald GM, Noor SW, lantaffi A, Grey J, Rosser BR. The relationship between use of sexually explicit media and sexual risk behavior in men who have sex with men: exploring the mediating effects of sexual self-esteem and condom use self-efficacy. Int J Sex Health. 2014;26(1):13-24.

52. Li H, Chen X, Yu B. Disclosure appraisal mediating the association between perceived stigma and HIV disclosure to casual sex partners among HIV+ MSM: a path model analysis. AIDS Care. 2016;28(6):722-5. doi:10.1080/09540121.2016. 1140884.

53. Bandura A. A social cognitive theory of personality. In: Pervin L, John O, editors. Handbook of personality (2nd ed.). New York: Guilford; 1999. p. 154-96.

54. Schunk DH, Gunn TP. Self-Efficacy and Skill Development: Influence of Task Strategies and Attributions. J Educ Res. 1986;79(4):238-44.

55. Stahlman S, Nowak RG, Liu H, et al. Online Sex-Seeking Among Men who have Sex with Men in Nigeria: Implications for Online Intervention. AIDS Behav. 2016; doi:10.1007/s10461-016-1437-3.

56. Greene GJ, Madkins K, Andrews K, Dispenza J, Mustanski B. Implementation and Evaluation of the Keep It Up! Online HIV Prevention Intervention in a Community-Based Setting. AIDS Educ Prev. 2016:28(3):231-45.

57. Liu H, Liu H, Cai Y, Rhodes AG, Hong F. Money Boys, HIV Risks, and the Associations between Norms and Safer Sex: A Respondent-Driven Sampling Study in Shenzhen, China. AIDS Behav. 2009;13(4):652-62.

\section{Submit your next manuscript to BioMed Central and we will help you at every step:}

- We accept pre-submission inquiries

- Our selector tool helps you to find the most relevant journal

- We provide round the clock customer support

- Convenient online submission

- Thorough peer review

- Inclusion in PubMed and all major indexing services

- Maximum visibility for your research

Submit your manuscript at www.biomedcentral.com/submit 